\title{
Study of Seismic Response Demands of Different L-shaped Buildings
}

\author{
Bharat Khanal ${ }^{1}$, Hemchandra Chaulagain ${ }^{2}$ \\ ${ }^{1}$ Post Graduate Student, MSc. in Structural Engineering, School of Engineering, Pokhara University, Pokhara, Nepal. \\ ${ }^{2}$ Assistant Professor, School of Engineering, Pokhara University, Pokhara, Nepal
}

E-mail: hchaulagain@pu.edu.np

Received on: $5^{\text {th }}$ May., 2020

Accepted for publication: $30^{\text {th }}$ Oct., 2020

\begin{abstract}
The present study evaluates the effect of plan configuration irregularity of different $\mathrm{L}$ shaped models. For this, one regular and six different L-shaped RC building frames were modeled for numerical analysis. The analysis was done through an equivalent static lateral force method and response spectrum analysis (dynamic analysis). The seismic response demands were measured in terms of story displacement, inter-story drift ratio, torsional irregularity ratio, and torsional diaphragm rotation. In addition, fundamental time period of structure, vibration mode shapes and modal participating mass ratios were also studied. The study shows that the fundamental time period of structure based on standard code shows a lower value as compared to a finite element approach. It is concluded that to account for the irregularities present within the buildings, current code provisions are insufficient and should be amended.
\end{abstract}

Keywords: Response spectrum analysis, Symmetrical building, Plan configuration irregularity, Seismic response demands.

\section{Introduction:}

Past research activities show that most of the existing buildings in Nepal exhibit inadequate seismic performance [1]. The common types of failures in $\mathrm{RC}$ construction are associated with the construction as well as structural deficiencies like building symmetry, detailing, and others [2]. To minimizes the earthquake-induced risk, it was essential to identify the seismic performance of the built environment. It was achieved through the development of different analytical procedures which ensures the structure to withstand during major earthquakes and produce enough caution whenever subjected to a major earthquake. The behavior of a structure during an earthquake depends on several factors; stiffness, adequate lateral strength, ductility, simple and regular configurations [3]. Among all the factors, the configuration of a building is an important feature that has a huge influence on the damage during the earthquake shaking $[4,5]$. In practice, a perfectly regular structure rarely occurs. Structural irregularities may vary dramatically in their nature and principle, are very difficult to define [6]. So, the selection of the building plan configuration plays a crucial role in the structural design for resisting earthquake ground shaking. The investigations on seismic action on buildings confirmed that irregular buildings undergo more damage than regular buildings [7, 8]. Thus, irregularities have to be studied and restrictions should be done on an irregular structure to avoid an abrupt change in mass and stiffness. 
2. Methodology:

The entire methodology can be represented in the following flow chart:

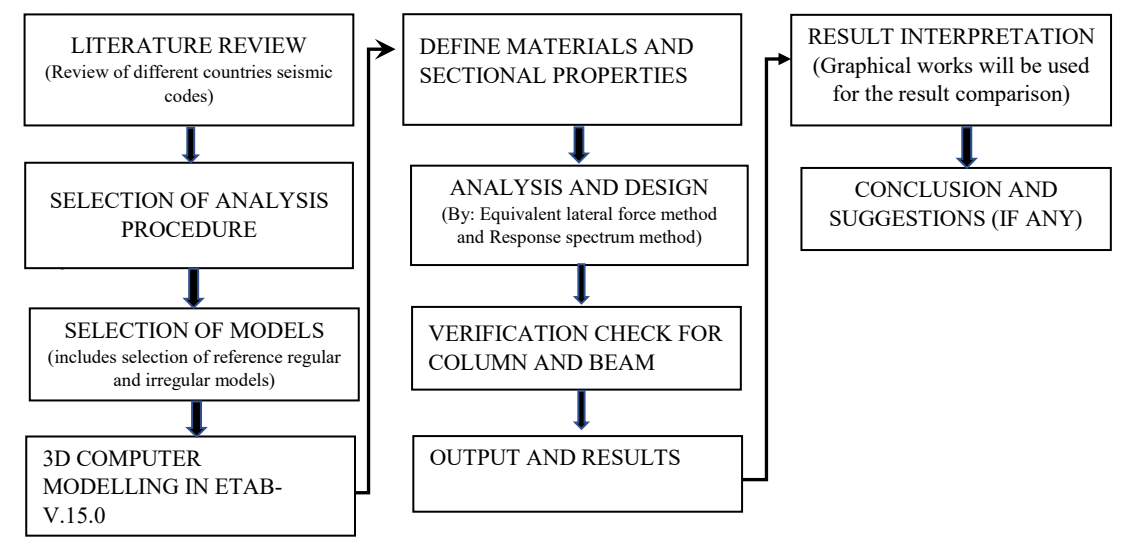

Figure 1: Flow chart for methodology

\section{Description of the Model's Understudy:}

The buildings undertaken for study have nine stories with a total height of the buildings above ground level being $28 \mathrm{~m}$ and $1.5 \mathrm{~m}$ below the ground level respectively. All stories are of $3 \mathrm{~m}$ height except ground floor which is $4 \mathrm{~m}$. The dimensions of the regular model floors are $45 \mathrm{~m}$ $\times 45 \mathrm{~m}$. The cross-sections of the construction elements determined using a preliminary design process are shown in Table 1.

Table 1: Structural Properties of the finite element model

\begin{tabular}{llc}
\hline $\begin{array}{c}\text { Type of } \\
\text { Structures }\end{array}$ & \multicolumn{1}{c}{ Multi-Story RC building } \\
\hline \hline $\begin{array}{l}\text { Number of } \\
\text { floors }\end{array}$ & \multicolumn{2}{c}{} \\
& Beam & $400 \times 350$ \\
& $\mathrm{~mm}^{2}$ \\
& Column & Table 2 \\
Elements & Slab Thickness & $130 \mathrm{~mm}$ \\
Dimension & Typical Story height & $3 \mathrm{~m}$ \\
& Ground floor story & $4 \mathrm{~m}$ \\
& height & $4.5 \mathrm{~m}$ \\
\hline \hline
\end{tabular}

Table 2: Reinforcement details of structural members.

\begin{tabular}{lcc}
\hline \multicolumn{1}{c}{ Floor } & $\begin{array}{c}\text { Optimized Column } \\
\text { cross section }\left(\mathbf{m m}^{\mathbf{2}}\right)\end{array}$ & $\begin{array}{c}\text { Optimized } \\
\text { Re-bars }\end{array}$ \\
\hline \hline 7th -9 th & $350 \times 350$ & $8-20 \phi$ \\
6th -7th & $350 \times 350$ & $12-20 \phi$ \\
5th -6th & $450 \times 450$ & $12-20 \phi$ \\
3rd -5th & $450 \times 450$ & $16-20 \phi$ \\
Base -3rd & $550 \times 550$ & $16-22 \phi$ \\
\hline \hline
\end{tabular}

For reference regular model, the floor slab is modeled as a rigid diaphragm while irregular finite element models are modeled as a semirigid diaphragm [9]. The dead load includes the self-weight of the building and an additional load resting on the floor taken as $1.5 \mathrm{kN} / \mathrm{m}^{2}$. A live load of $2.5 \mathrm{kN} / \mathrm{m}^{2}$ is considered on the typical floor and $1.0 \mathrm{kN} / \mathrm{m}^{2}$ at the roof. The total seismic weight of the building is taken as $100 \%$ of dead load and $25 \%$ of the live load. The concrete mix defined for the column, beam/slab is taken as M25 and M20, respectively. Fe-500 and Fe-415 grade rebar is used as a longitudinal and confinement bar. The seismic design has been done with the assumption of medium soil sites (type II); importance factor is equal to 1.0; Seismic zone factor $(\mathrm{z})$ for the zone $(\mathrm{v}), \mathrm{z}=$ 0.36 ; building damping ratio $=5 \%$.

\section{Result and Discussion:}

\subsection{Fundamental Time Period:}

The fundamental period based on IS code is 0.95

$\mathrm{s}$, whereas the fundamental period of the RM and different L-shaped models based on the FE approach ranges from 1.69 to $1.67 \mathrm{~s}$ [Table 3], which reaches $178-176 \%$ for the regular and irregular configuration that introduced in the code provisions which shows that the time periods computed from the empirical expression are relatively shorter than those computed from the structural models. Hence it is clear that the code formulas have a significant defect in the 
calculation of vibration period which is considered the main parameter for lateral force procedure. The similar conclusion has been made by Ehsan et al and Monish S. in their study $[10,11]$.

Table 3: Fundamental vibration mode shape

\begin{tabular}{cccccccc} 
Studied Building models & RRM & IRM L1 & IRM L2 & IRM L3 & IRM L4 & IRM L5 & IRM L6 \\
$\begin{array}{c}\text { 1st Fundamental vibration } \\
\text { mode shape, sec }\end{array}$ & 1.69 & 1.69 & 1.68 & 1.68 & 1.67 & 1.67 & 1.67 \\
\hline
\end{tabular}

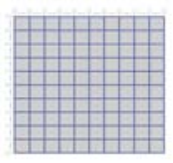

(a)

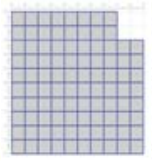

(b)

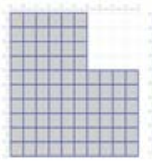

(c)

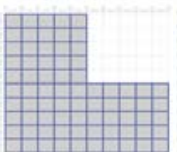

(d)

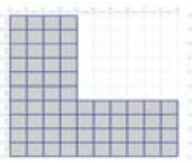

(e)

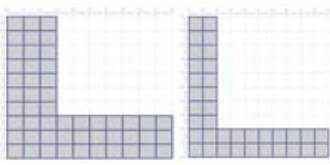

(f)

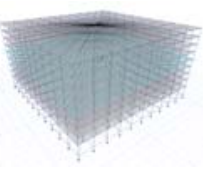

(g) (h)

Figure 2: Finite element models under study (a) Reference regular model (RRM) (b) Irregular model L1 (IRM L1) (c) Irregular model L2 (IRM L2) (d) Irregular model L3 (IRM L3) (e) Irregular model L4 (IRM
L4)
(f) Irregular
model L5 (IRM
L5)
(g) Irregular
model
(IRM L6).

\subsection{Vibration Mode Shapes}

The vibration modes could be pure $\mathrm{x}$ or $\mathrm{y}$ translational or rotational mode for the reference symmetric buildings without re-entrant/torsional irregularity. It is noted that for regular and nearly regular building models the first two modes are pure translational and third mode is pure torsional however for irregular models with an increase in the degree of irregularity, the modes become mixed translational and torsional. In this study, for RRM and IRML1, the first two modes are purely translational and the third one is rotational while for IRM L2, the first mode is purely translational, the second and third mode is purely rotational whereas for IRM L3-L6 the vibrational modes are of mixed type.

\subsection{Modal Mass Participation Ratio:}

The study shows that for IRM L1 -IRM L6, the number of modes to achieve target mass participation ratios of $90 \%$ of the total seismic mass are: $8,8,8,9,10$, and 11 , respectively. This confirms that the number of modes should be accounted, increase with irregularity increase, which is similar to the conclusion made by Liang et al (2012) in their study that with an increase in the irregularity of the structure, the larger number of modes is required for accurate determination of the dynamic response of the structure [12].

\section{Seismic Response Demands:}

\subsection{Maximum Story Displacement:}

Figure 3 shows the story displacement response demand distribution along with each model's height. Irregular model IRM L6 displays the maximum top displacement response of 128.50 mm which is $132 \%$ that of the RRM. The lateral displacement response demands increase with the increase of configuration irregularity level. The corresponding maximum top displacement for IRM L1, IRM L2, IRM L3, IRM L4, IRML5 are: 97.40 (100\%), 99.20 (101.85\%), 100.60 (103.3\%), 101.20 (103.9\%), 116.50 (119.61 $\%$, respectively.

The maximum inter-story drift responses are 00.005576 (100.7228\%), $0.005677(102.54 \%)$, $0.005727 \quad(103.46 \%), \quad 0.00614 \quad(110.861 \%)$, 0.006457 (116.637\%), 0.007382 (133\%) for IRM L1, IRM L2, IRM L3, IRML 4, IRM L5, IRM L6, respectively which confirms the significant effect of floor irregularity.

\subsubsection{Effect of Lateral-Torsional Coupling in the Story Displacement}

Figure 3(b) indicates that maximum response is induced in the IRM L6. The maximum ydirection displacement demands induced in perpendicular to applied EQ direction are 40.70 $\%, 14.59 \%, 14.13 \%, 6.26 \%, 1.8 \%, 1.44 \%$, $0.103 \%$ for IRM L6, IRM L5, IRM L4, IRM L3, IRM L2, IRM L1, and RRM respectively which confirms that the lateral displacement response demand increases gradually with the configuration irregularity of the building model. 

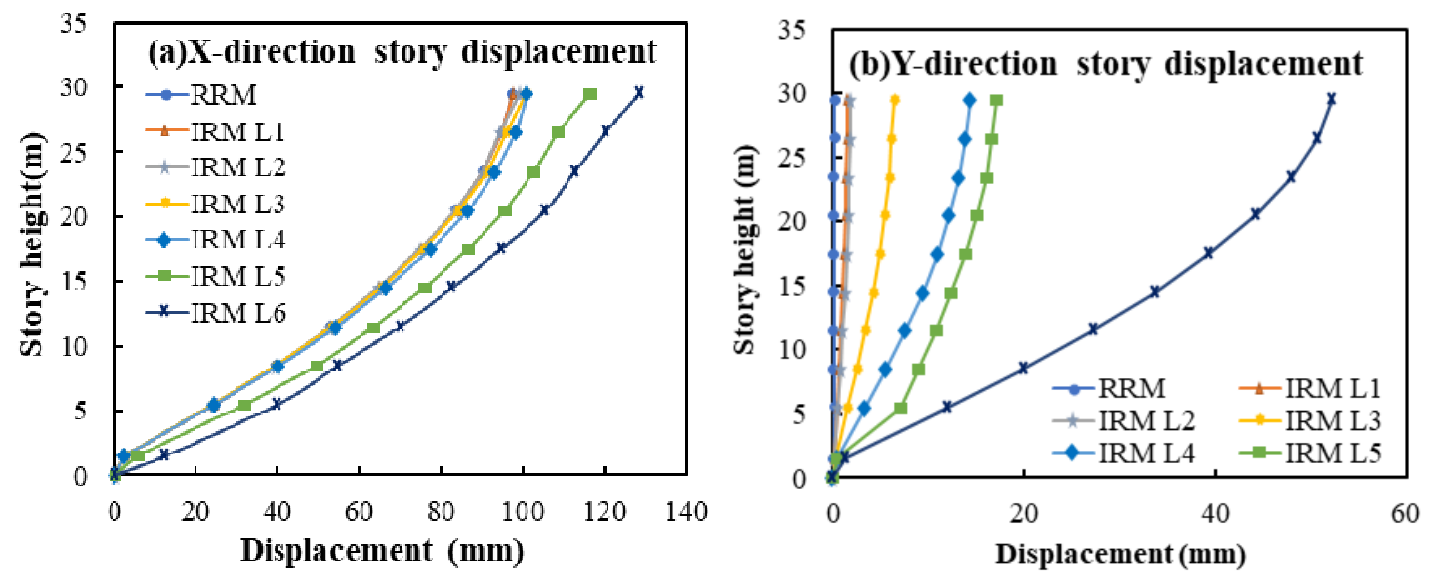

Figure 3: Story displacement of different models along with the height. (a) X-direction response (b) Ydirection response

\subsection{Maximum Inter-story Drift Ratio:}

The story drift ratios over the building's height for different models are introduced in Figure 4. The inter-story drift ratio response attains its maximum value in model IRM L6 and reaches the value of 0.007382 ; that is $33 \%$ higher than that of reference regular model.

\subsubsection{Effect of Lateral-Torsional Vibration Coupling in the Story Drift Ratio:}

Figure 4 (b) shows that for symmetrical/regular and nearly regular models, the y-direction response is very small, however, for torsionally irregular models' significant contribution is observed. IRM L6 gets the maximum contribution of perpendicular to EQ direction that is $36.37 \%$ of EQ direction.

\subsection{Torsional Irregularity:}

The torsional irregularity ratio is defined to exist where the maximum story drift, computed including accidental torsion, at the end of the structure transverse to an axis is more than 1.2 times the average of the inter-story drift at the end of the structure [13]. Figure 5 (b) shows the maximum value of the torsional irregularity ratio for different model types. The maximum torsional irregularity values developed are 1, $1.01,1.02,1.05,1.09,1.11$ for IRM L1, IRM L2, IRM L3, IRM L4, IRM L5, and IRM L6, respectively. The graph also displays that with the increase in plan irregularity of models the maximum torsional irregularity ratio values increases and tend to reach the upper code limit value of 1.2 .

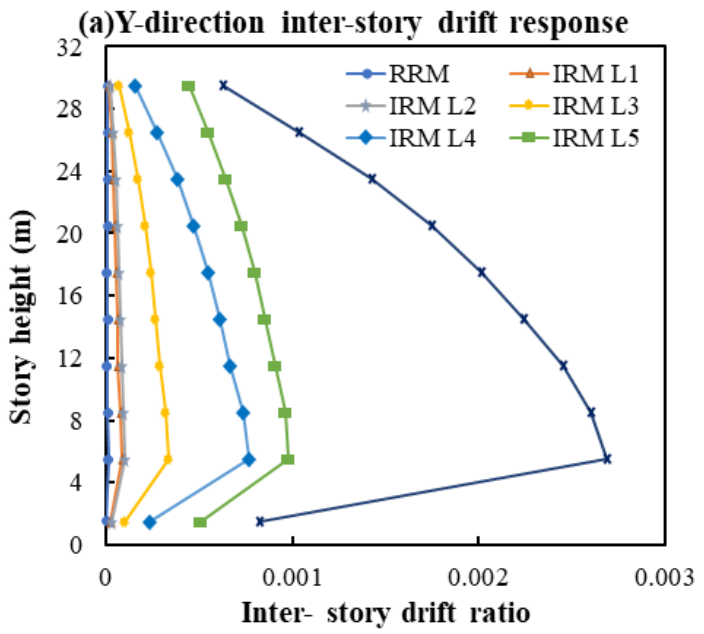

Figure 4: Inter-story drift ratio along with the height. (a) X-direction response (b) Y-direction response 

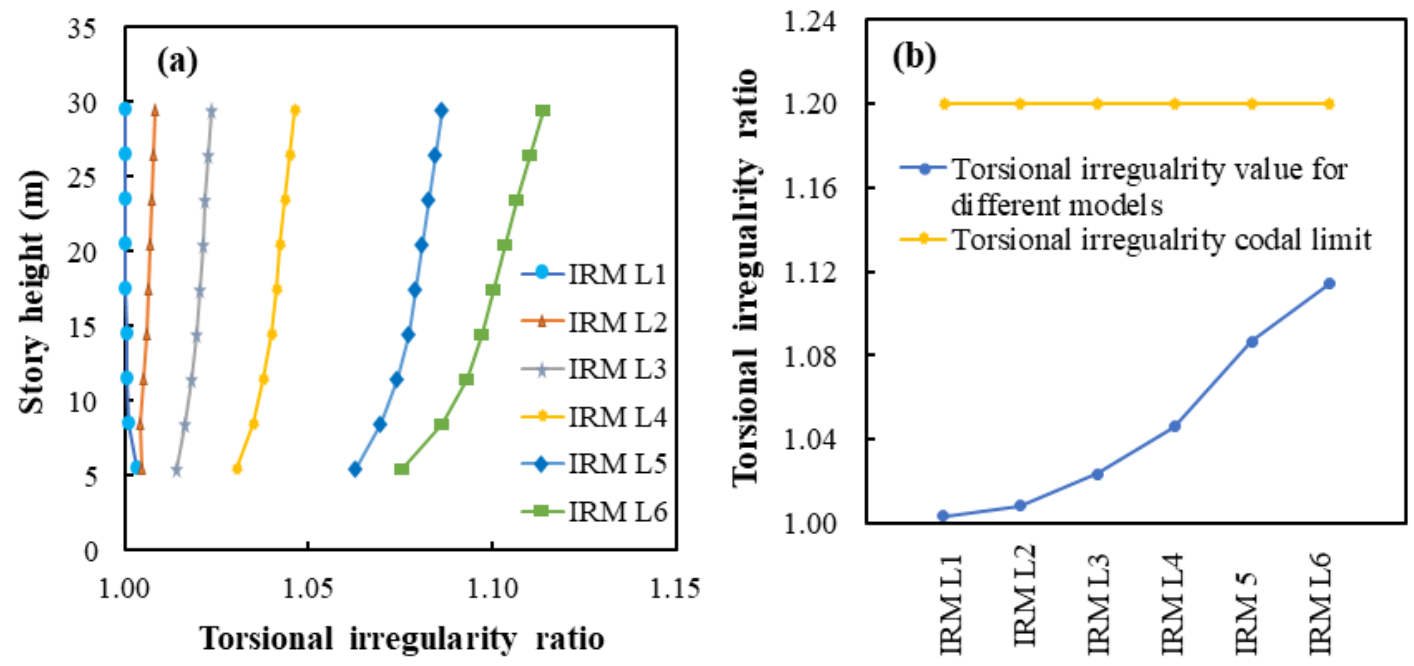

Figure 5: Torsional irregularity ratio (a) Torsional irregularity ratio of different models along with height (b) Maximum torsional irregularity of different models.
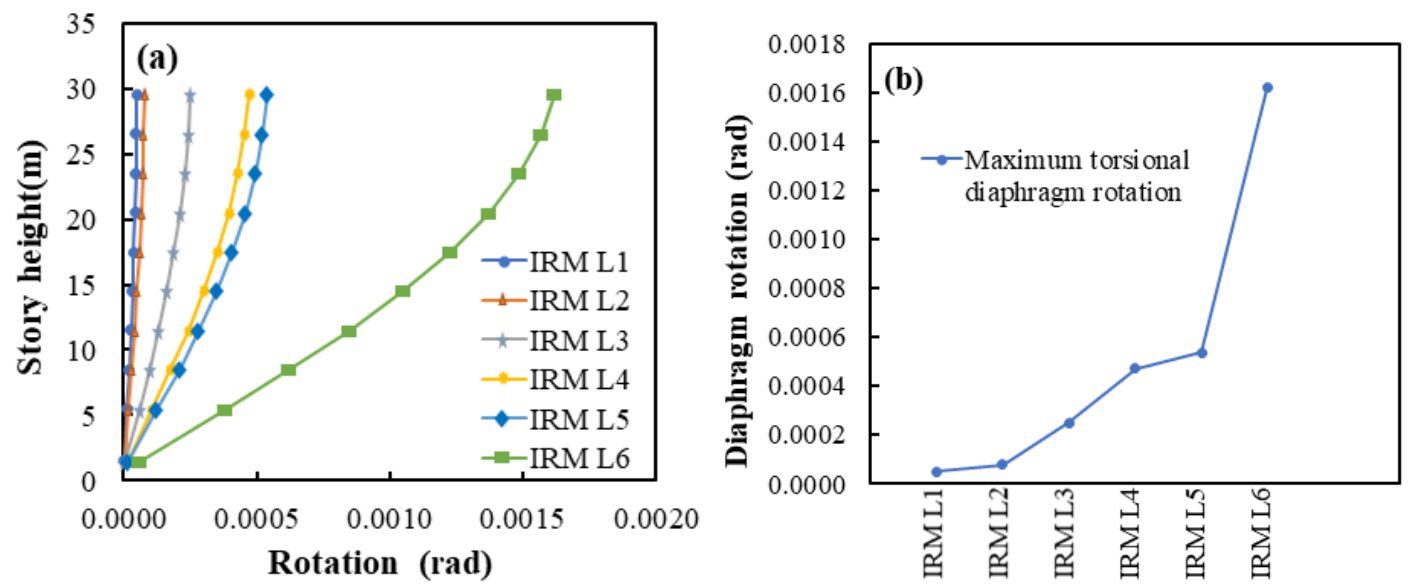

Figure 6: Torsional diaphragm rotation, (a) Torsional diaphragm rotation of different L-shaped models along with height (b) Maximum torsional diaphragm rotation of models

\subsection{Floor Diaphragm Torsional Rotation:}

Figure 6 (a) shows that the torsional diaphragm rotation slightly changes along the height of the building reaching a maximum value at the top level, which is also the same conclusion made by Özmen et al in their study [14]. The maximum torsional rotation response demands are: $0.0005, \quad 0.0000800,0.00025,0.0005380$, $0.0004700,0.0016170$ radian for IRML1-IRM L6 respectively. The maximum torsional diaphragm rotation for different models is shown in Figure 6(b). The graph shows that with the increase in the plan irregularity of models, the torsional diaphragm rotation value increases and attains the minimum value for the nearly regular model (IRM L1) and maximum value for irregular building (IRM L6), respectively.

\section{Conclusions:}

The empirical expression for the determination of time period as mentioned in standard codes shows a lower value than the one calculated by the finite element approach. This shows that the code formula for estimating the time period doesn't account for the irregularities present within the building. Hence the code formula for determining the time period is insufficient to include all the responses when subjected to the earthquake excitation and should be amended. The study of mode shape shows that for regular or nearly regular building, the first and second 
modes are purely translational and the third mode is purely rotational. While as with the increase in the irregularity of the building the mode shapes become completely of mixed type. The study shows that with the increase in the irregularity of building, the number of modes to achieve $90 \%$ of modal mass participation for accurate determination of dynamic response increases. Under the unidirectional application of earthquake loading, the response induced in the perpendicular direction to earthquake excitation increases with increases in the plan irregularity due to lateral-torsional coupled behavior of the irregular building.

\section{Suggestions and Recommendations}

The one probable solution that can be applied to reduce the irregularity effects in the building is by upholding the good co-operation between the architecture and structural engineer from the early planning phase of the building construction [15].

A study on seismic behavior of asymmetric RC building with re-entrant corner plan configurations under bidirectional seismic excitation in the context of nonlinear time history analysis under different earthquake data by considering gravity load and compare the results with non-linear static analyses can be taken into consideration for future works.

\section{Acknowledgements:}

I would like to forward my deepest appreciation and gratitude to Pokhara University, Nepal and my supervisor Dr. Hemchandra Chaulagain for his patience and constructive advice. Last but certainly not least, I would like to thank my family members and friends for their invaluable support.This research received the fund from Pokhara University Research Centre (PURC), Pokhara University.

\section{Conflict of Interest}

The authors declare that they have no known competing financial interests or personal relationships that could appeared to influence the work reported in this paper

\section{References:}

[1] Chaulagain H, Rodrigues H, Spacone E, Varum H.," Seismic response of current RC buildings in Kathmandu Valley," Structural Engineering and Mechanics, 53(4),791-818,2015.

[2] Gautam D, Rodrigues H, Bhetwal K, Neupane P, Sanada Y,''Common structural and construction deficiencies of Nepalese Buildings,' Infrastruct.Solut, 1:1, 2016.

[3] M. Ravikumar, S Babu, V. Sujith, Reddy V,' Effect of irregular configurations on the seismic vulnerability of RC buildings," Architecture Research,2(3),20-26,2013.

[4] Kabir, R., D. Sen, and M. Islam," Response of multi-storey regular and irregular buildings of identical weight under static and dynamic loading in context of Bangladesh," International Journal of Civil \& Structural Engineering, 5(3),252-260, 2015.

[5] Islam, S. and M. M. Islam,' Analysis on the structural systems for drift control of tall buildings due to wind load: critical investigation on building heights," The AUST Journal of Science and Technology,5(1), 2014.

[6] Wood SL," Seismic response of RC frames with irregular profiles," Journal of Structural Engineering; 2, 118,54566, 1992.

[7] Haque M, Ray S, Chakraborty A, Elias M, Alam I," Seismic Performance Analysis of RC Multi-Storied buildings with Plan irregularity," American J of Civil Eng, 4(3),68-73, 2016.

[8] Abdel Raheem S E, Ahmed M M M, Ahmed M M, Abdel-shafy G A A," Evaluation of plan configuration irregularity effects on seismic response demands of L-shaped MRF building," Earthquake Eng, 16:3845-3869,2018.

[9] Jereen A T, Anand S, Issac B M,'SSeismic Evaluation of Buildings 
Himalayan Journal of Applied Science and Engineering (HiJASE), Vol. 1, Issue 1, No. 11, 2020

with Plan Irregularity," Applied Mechanics and Materials, 857:225230,2016 .

[10] Ehsan S F, Rao K R M, Bahador B,' Determination of time period of vibration effect on seismic performance of building," Applied Mechanics and Materials,330:878-883, 2013.

[11] Monish S, Karuna S," A study on seismic performance of high-rise irregular RC framed buildings," International Journal of Research in Engineering and Technology,4(5):340346. 2015.

[12] Liang Z, Lee C G, Dargush F G, Song J," Structural damping: applications in seismic response modification," CRC Press, Boca Raton, 2011.
[13] IS 1893-2002 (Part-1) Criteria for Earthquake resistant design of structures, General provisions and buildings. Bureau of Indian Standards, New Delhi ,2002.

[14] Özmen G, Girgin K, Durgun Y," Torsional irregularity in multi-story structures," Int J Adv Struct Eng, 6(4),121-131, 2014.

[15] Mohod V M," Effect of Shape and Plan Configuration on Seismic Response of structure,' International Journal of scientific and Technology, 4(09). 2015. 